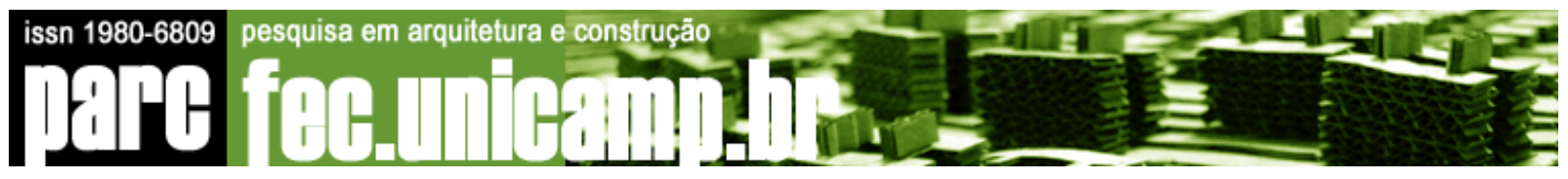

\title{
A Vila Riza e a Destruição do Patrimônio Ferroviário Campineiro
}

\section{The Riza Village and Campinas' Railroad Heritage Destruction}

ALINE RUSSO BERTUCCELLI

ANDRÉ DAL'BÓ DA COSTA

ANDRÉ RIBEIRO DE BARROS

KAYA LAZARINI

TAIMÊ BERTAGNA

Todos os autores são estudantes de arquitetura e urbanismo na Faculdade de Engenharia Civil, Arquitetura e Urbanismo da Universidade Estadual de Campinas, UNICAMP. Uniram-se pelo desejo comum de estudar o patrimônio sob o enfoque habitacional, por isso o caso da Vila Riza apresentado neste texto.

alinebertu@gmail.com

andredalbo@gmail.com

andrerb@gmail.com

kaya.lazarini@gmail.com

taimebertagna@yahoo.com.br

\section{Resumo}

No dia 13 de abril de 2007, na cidade de Campinas, no interior de São Paulo, os últimos exemplares habitacionais com arquitetura de tipologia ferroviária/fabril, singulares e representativos, foram demolidos para dar lugar à nova rodoviária da cidade a ser inaugurada no ano próximo. Duas dessas construções foram poupadas e se transformarão em museu! O objetivo deste texto elaborado por um grupo de alunos do curso de Arquitetura e Urbanismo da Faculdade de Engenharia Civil, Arquitetura e Urbanismo, é o de registrar e noticiar a ação de demolição das casas da Vila Riza, no bairro da Vila Industrial de Campinas, para fomentar reflexões à respeito da preservação do patrimônio ferroviário e industrial da cidade.

Palavras chave: Patrimônio Ferroviário - Patrimônio Histórico - Patrimônio Arquitetônico. 


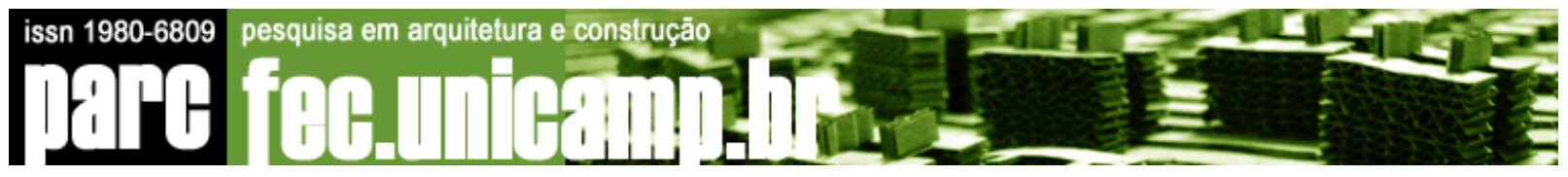

\section{Abstract}

April 13th 2007: The last examples of unique and representative industrial/railroad type of housing were demolished to build the city's newest bus station in Campinas, city in the countryside of São Paulo State. Two houses were spared and they will be transformed into museums. Written by Architecture students from the School of Civil Engineering, Architecture and Urban Design, this text's main goal is to register the actions taken on Vila Riza, in Vila Industrial district in Campinas.

Keywords: railroad, historical, cultural and industrial heritage.

\section{A VILLA RIZA E A DESTRUIÇÃO DO PATRIMÔNIO FERROVIÁRIO CAMPINEIRO}

“(...) tudo aquilo que foi, e não é mais hoje em dia. No momento atual, nós acrescentamos ainda a esse termo a idéia de que aquilo que foi não poderá jamais se reproduzir, e que tudo aquilo que foi constitui um elo insubstituível e intransferível de uma cadeia de desenvolvimento". ${ }^{1}$ (WIECZOREK, 1984, P.23)
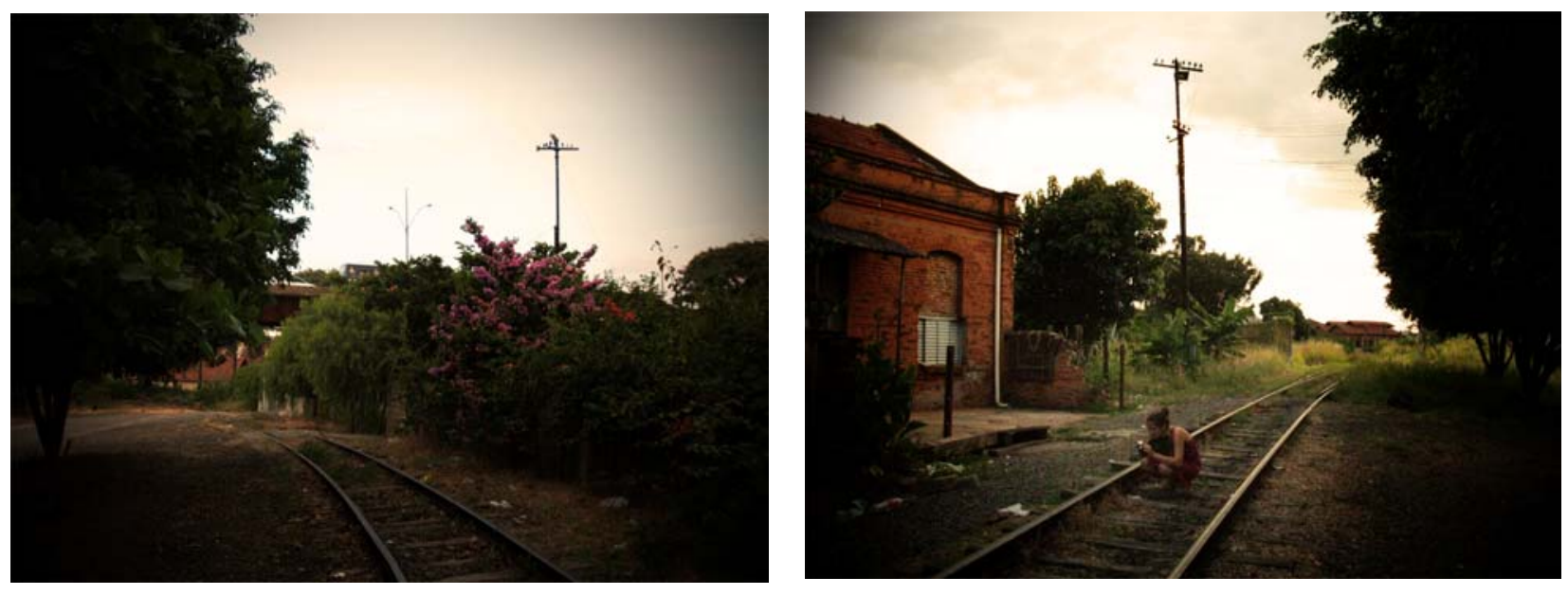

\footnotetext{
${ }^{1}$ WIECZOREK, Daniel. Introduction du traducteur. In: RIEGL, Aloïs. Le culte moderne des monuments. Son essence et sa genèse. 1984, p. 23.
} 
No início do ano de 2007, o objetivo do nosso grupo era o de desenvolver um trabalho acadêmico para a disciplina AU814: "Técnicas Retrospectivas em Arquitetura", da Faculdade de Engenharia Civil, Arquitetura e Urbanismo da Unicamp, que propunha como tema de pesquisa e trabalho final de curso o inventário de vários edifícios que compõem o patrimônio ferroviário campineiro.

Interessava à disciplina promover reflexões a respeito das condições atuais de conservação dos prédios, de seus usos e das iniciativas de preservação públicas vigentes, para que discutíssemos diretrizes de projeto e, principalmente, os parâmetros de conservação e restauração adequados ao caso. Nosso grupo escolheu um conjunto de pequenas habitações ferroviárias que compõem a chamada Vila Riza.

Logo no início das visitas a campo para levantamentos métricos e registros fotográficos percebemos a grandiosidade e importâncias do conjunto do qual as casinhas que estudaríamos eram parte integrante. No entanto, também já nos primeiros contatos com seus moradores, tomamos conhecimento de que em breve espaço de tempo tais edificações seriam demolidas, em função da construção de um outro empreendimento.

Observamos também que aquilo que antes seria um mero levantamento de campo havia tomado outras proporções, outras direções, levando-nos a novos questionamentos a respeito das políticas públicas de preservação. A notícia de que nossos objetos de estudo não mais existiriam dali a algumas semanas, por qualquer que fosse o motivo, tornava o grupo impotente e desiludido perante a situação. Com a constatação do desinteresse de muitos pela preservação da memória física da cidade sobrepôs nosso interesse acadêmico inicial; interessava agora refletir sobre que tipo de conservação vem sendo praticada em relação ao patrimônio arquitetônico e cultural. O que afinal, em Campinas, tem sido selecionado para permanecer ou desaparecer como testemunho da história física da cidade?

Assim, o objetivo deste texto é o de registrar e noticiar a ação de demolição das casas da Vila Riza. Demolições que, a nosso ver, só corroboram a idéia de falta de planejamento e incentivo a estudos técnicos sobre edifícios históricos, refletindo um enorme descaso por parte do setor público com o patrimônio ferroviário da cidade Campinas. Esse descaso é dissimulado. Costuma vir mascarado por intervenções "cosméticas de restauro' (ou serão reformas em estilo?) que ocorrem em edifícios isolados, que servem para fragmentar espacialmente áreas urbanas consolidadas na memória dos habitantes - dotadas de riqueza cultural/documental - para dar lugar ao objeto novo, modernizante. Muitos conjuntos de edifícios históricos, estreitamente ligados ao processo de desenvolvimento das cidades e da malha urbana, a exemplo da Vila Riza, permanecem pouco estudados. Pelo contrário, este vem sendo indiscriminadamente substituído por construções e/ou restauros de forte apelo midiáticos. Renovam-se as construções antigas, substituem-se as casas velhas em prol de duvidosa modernidade. Ignora-se assim a possibilidade de integração da cidade com o patrimônio que lhe agrega valor cultural, sentido, identidade. 
Patrimônio. Ao procurarmos em qualquer dicionário da língua portuguesa, encontramos a origem do latim, patrimonium, que, dentre outros significados, corresponde à herança. Segundo Françoise Choay, "esta bela e antiga palavra estava, na origem, ligada às estruturas familiares, econômicas e jurídicas de uma sociedade estável, enraizada no espaço e no tempo. Requalificada por diversos adjetivos (genético, natural, histórico, etc.) que fizeram dela um conceito "nômade", ela segue hoje uma trajetória diferente e retumbante." ${ }^{2}$ (CHOAY, 2001, p.11)

Nesta direção, 'Patrimônio Histórico', atualmente, indica um bem que acumula elementos históricos, arquitetônicos, ambientais, ecológicos, científicos, para os quais se dotam valores que permitem identificar a memória e/ou referência de um modo de vida ou identidade dos povos.

Já a expressão 'Patrimônio Cultural' transcende a idéia de 'edifício' na sua materialidade arquitetônica, agregando e remetendo a outras categorias de percepção dos objetos da história, uma vez que ao longo dos tempos, além dos valores de memória vão sendo agregados valores de contemporaneidade. Convém frisar que principal característica do termo "Patrimônio", independentemente da sua adjetivação, é a atribuição de valor que damos a um bem para transformá-lo em herança cultural. Uma civilização pode ou não reconhecer um objeto, um edifício como parte representativa da memória de determinada época, de seu passado; tudo depende da atualização que é capaz de fazer dos significados deste mesmo passado.

\section{Campinas e seu parque ferroviário}

A transformação do entendimento do termo 'patrimônio' nas práticas e políticas públicas atuais, como potencial turístico vazio, como produto de consumo e espetáculo, banaliza a dimensão fundamental que o inaugura. O patrimônio ferroviário e industrial, em especial nas cidades emergentes vem sendo constantemente sucateado na contramão das diretrizes da UNESCO (Organização das Nações Unidas para a Educação, a Ciência e a Cultura), que visa à preservação contemporânea dos edifícios/sítios que compõe a herança cultural dos povos.

Na zona central da cidade de Campinas, Estado de São Paulo, em uma área pertencente à RFFSA Rede Ferroviária Federal S. A. - encontra-se um conjunto de edifícios que representa material e simbolicamente a evolução urbana e tecnológica da cidade, desencadeada pela expansão da rede ferroviária pelo interior do Estado decorrência da economia cafeeira do final do século XIX. O conjunto da RFFSA é, portanto, nossa herança cultural.

${ }^{2}$ CHOAY, Françoise. A Alegoria do Patrimônio. São Paulo: Editora da UNESP, 2001 


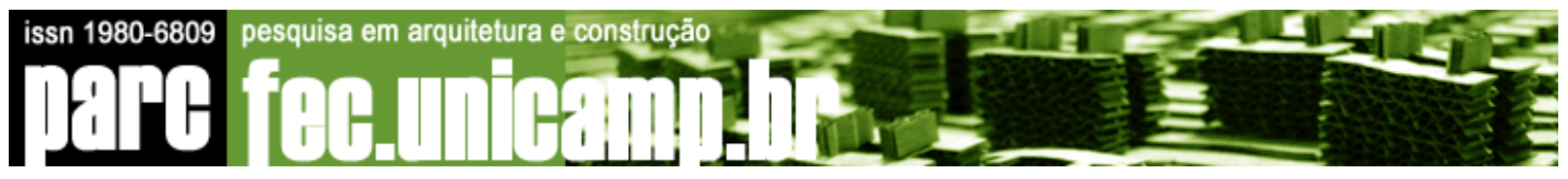

Assim esse domínio do patrimônio-cultural não se limita aos edifícios reconhecidos como ícones deste período, a exemplo a Estação Ferroviária de Campinas - FEPASA, mas estende-se a prédios de serviços e residências a ela relacionados e a própria malha urbana que circunscreve. É nesta ótica que o grupo de pequenas casas ferroviárias que estudaríamos - que estão no chão - têm a mesma importância histórica e cultural da estação e dos demais edifícios maiores.

O referido parque ferroviário de aproximadamente $280.000 \mathrm{~m}^{2}$, situado na região central de Campinas, comportou a partir de 1868 as seguintes companhias ferroviárias: Companhias Paulista (1868), Mogiana (1872), Ramal Férreo (1889), Funilense (1890) e Sorocabana (1921).

\section{Vila Riza, A que acabou.}

Datada do primeiro quartel do século XX, a 'Vila Riza', era formada originalmente para abrigar as famílias dos trabalhadores da extinta Companhia Ferroviária, por oito edifícios principais: três casas da turma, casa do mestre de linha, casa do chefe, casa do instrutor de maquinas, deposito do óleo do tráfego.

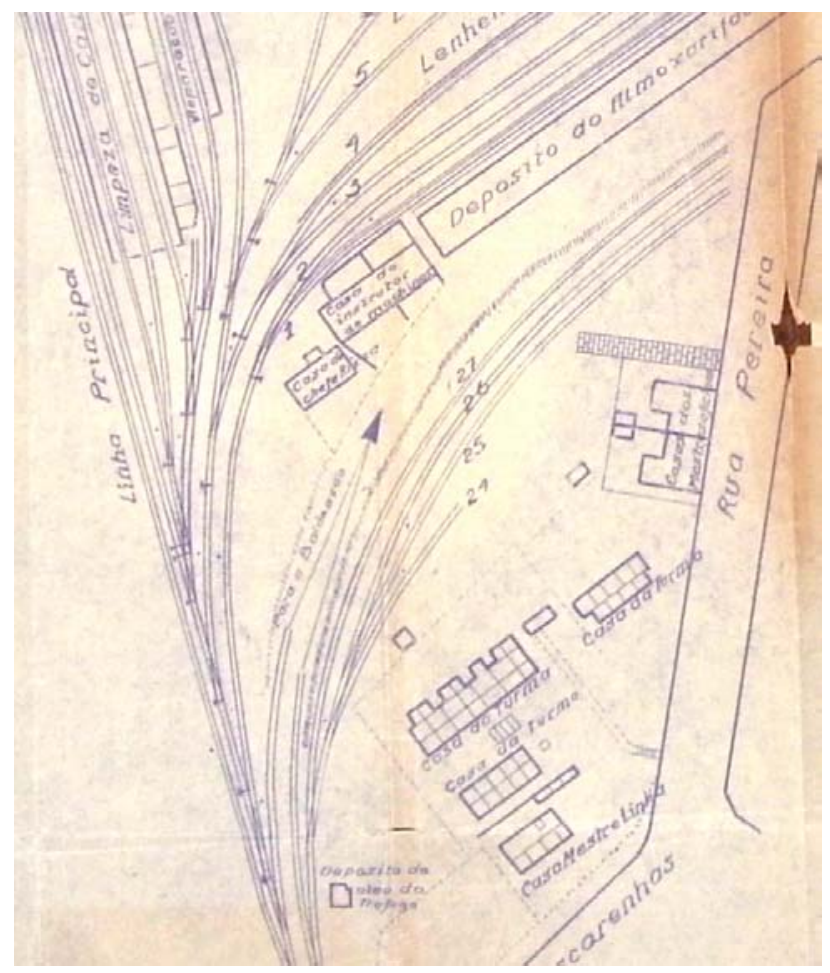

Imagem 1: implantação da Vila Riza. Fonte: Condepacc. s/d. 


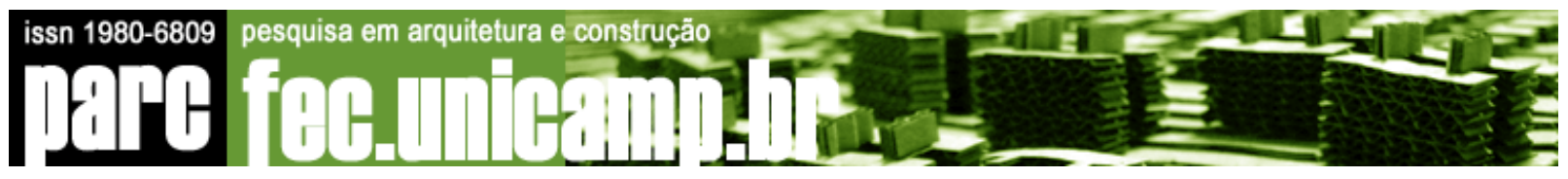

Essas construções caracterizam-se por uma arquitetura de tipologia ferroviária, à inglesa, com tijolos aparentes ou com reboco avermelhado, com frisos para imitar tijolos; tratamentos característicos do estilo. Em algumas casas percebem-se claras referências aos edifícios fabris do mesmo período, com seus característicos frontões e beirais. As casas da Vila Riza eram, portanto, exemplares importantes sob o aspecto documental da arquitetura, uma vez que, como nunca haviam sido alteradas desde a construção, possibilitavam estudos detalhados de partidos habitacionais e materiais construtivos usados à época de grande interesse para as disciplinas do restauro e da história da arquitetura regional. Seu caráter, sobretudo residencial, garantia ao complexo relevância sociocultural, já que seus moradores mantinham viva esta parte da memória campineira ao preservarem as casas ocupadas e em bom estado de conservação.
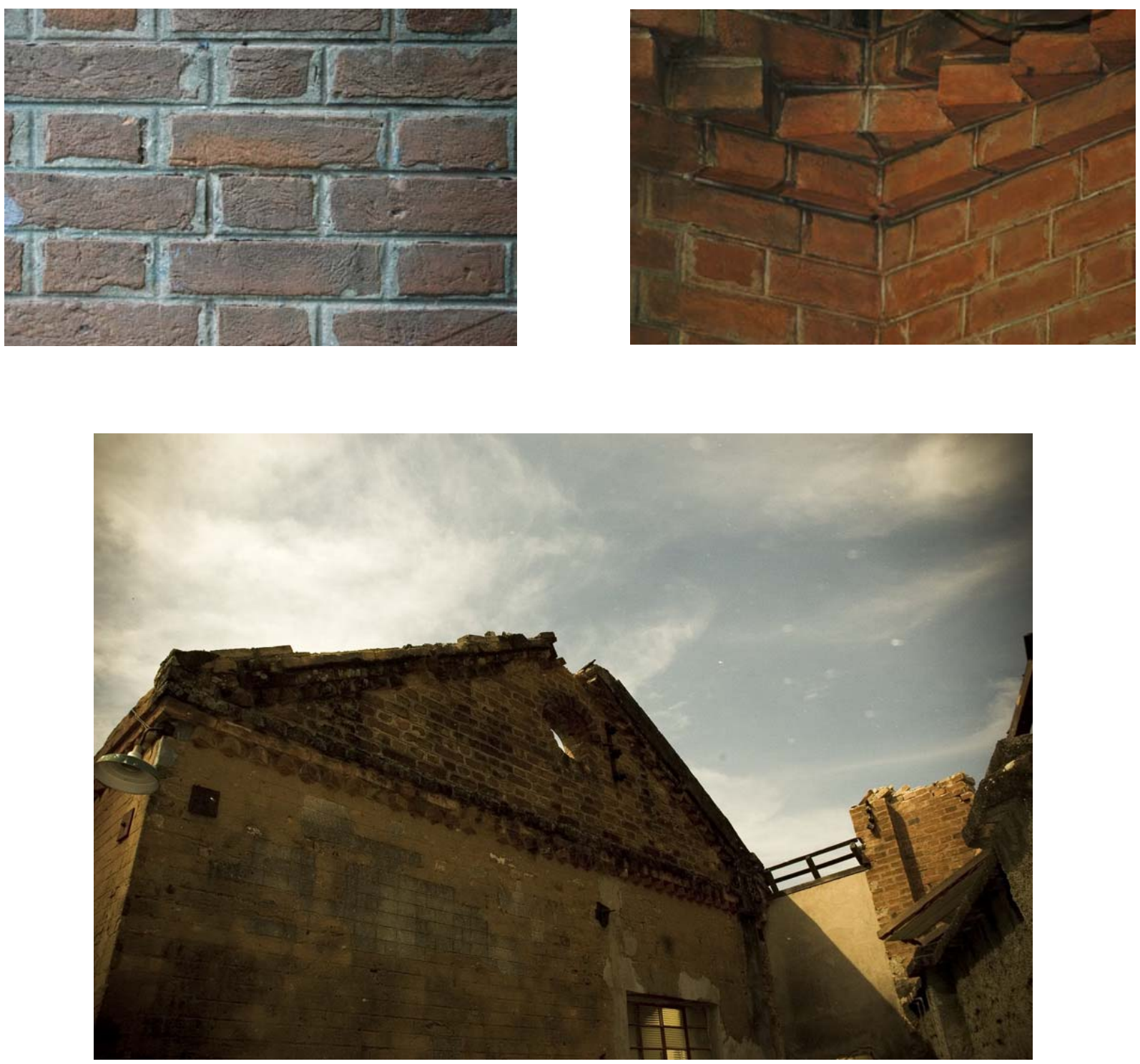
Como já mencionado, além de seus valores arquitetônicos, a Vila Riza configurava-se também em testemunho destacado da história da urbanização da cidade. Sua relevância na definição do desenho da cidade, acreditamos, relaciona-se diretamente à dinâmica de uma cidade bipartida devido ao crescimento urbano desordenado e que teve como eixo de separação exatamente a antiga estrada de ferro, em cujas margens situava-se a Vila Riza.

Atualmente propriedade da Prefeitura Municipal de Campinas, A Vila Riza teve seu processo de tombamento de número 06/04 junto ao Conselho de Defesa do Patrimônio Cultural de Campinas CONDEPACC - feito em 2004 foi arquivado! No local da demolição, margeado por viadutos e vazios potenciais urbanos, será construída a nova rodoviária da cidade.

O novo Terminal Rodoviário de Campinas surge como parte de um projeto maior e de caráter metropolitano, o Corredor Noroeste. Dentre as características apresentadas pelos responsáveis do projeto da nova rodoviária, está a relação positiva do projeto com o patrimônio histórico do entorno. Apesar de salientarem isso no memorial do projeto, tanto a Prefeitura quanto os participantes do empreendimento optaram por manter apenas parte do conjunto de casas da Vila Riza, desconfigurando sua dinâmica original e, destruindo assim, possivelmente, os últimos modelos dessa tipologia de arquitetura ferroviária.

O mais surpreendente é que a Prefeitura Municipal de Campinas, responsável pela demolição quase total do conjunto, não possui qualquer tipo de arquivo ou documentação consistente que sequer confirme a existência da Vila. Conforme constatamos em nossas pesquisas de arquivo, são poucas as peças gráficas disponíveis. Existem apenas plantas mal conservadas de implantação/localização e que dificultam o desenvolvimento de pesquisas como a que pretendemos desenvolver: inventários técnicos do patrimônio arquitetônico campineiro.

Essas demolições ocorreram no dia 13 de abril de 2007, restaram duas casas que, poupadas das escavadeiras e se transformarão em um museu - o Museu do Trem! 


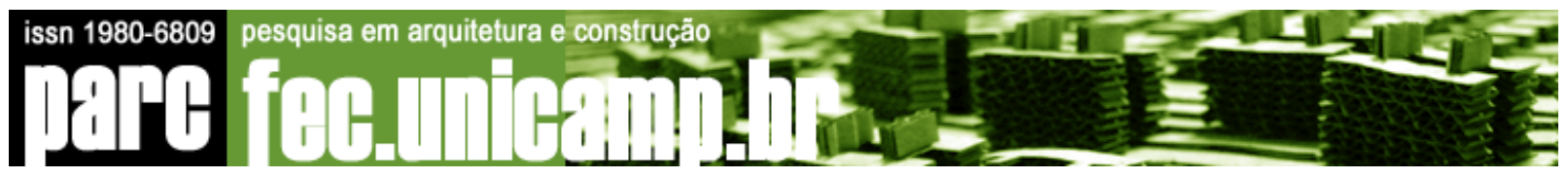

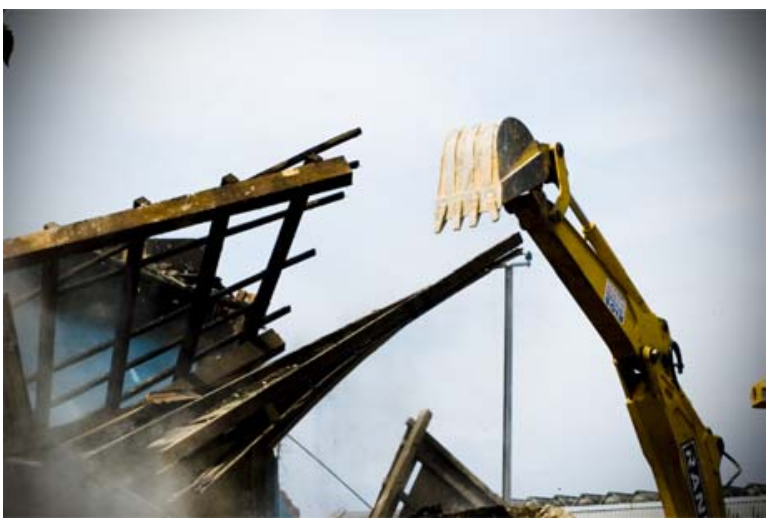

Foto 01: Cena do início da demolição.

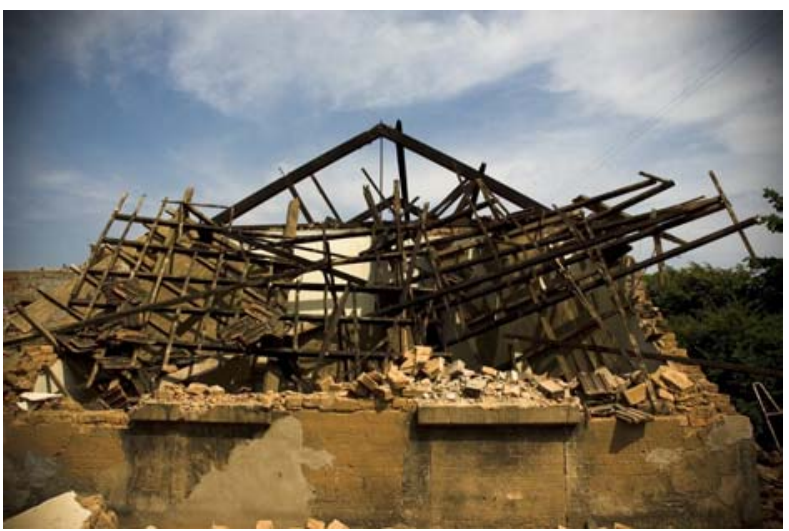

Foto 03: Escombros do madeiramento do telhado.

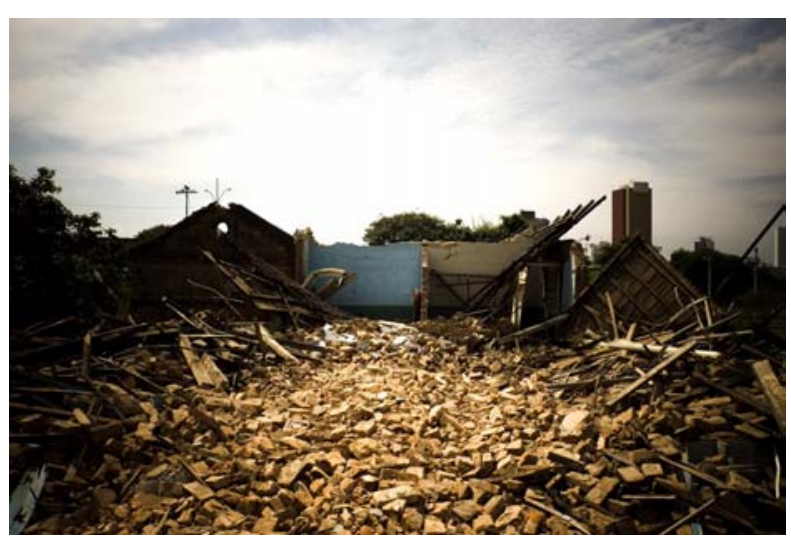

Foto 05: Cena da destruição.

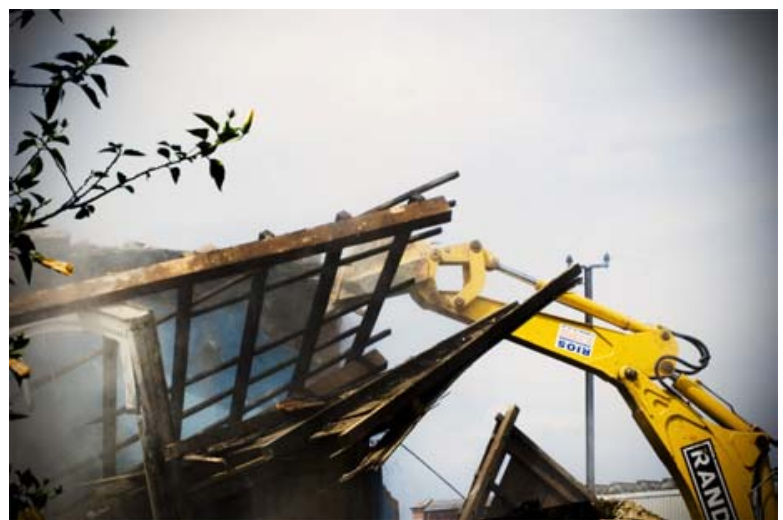

Foto 02: Destruição do madeiramento do telhado

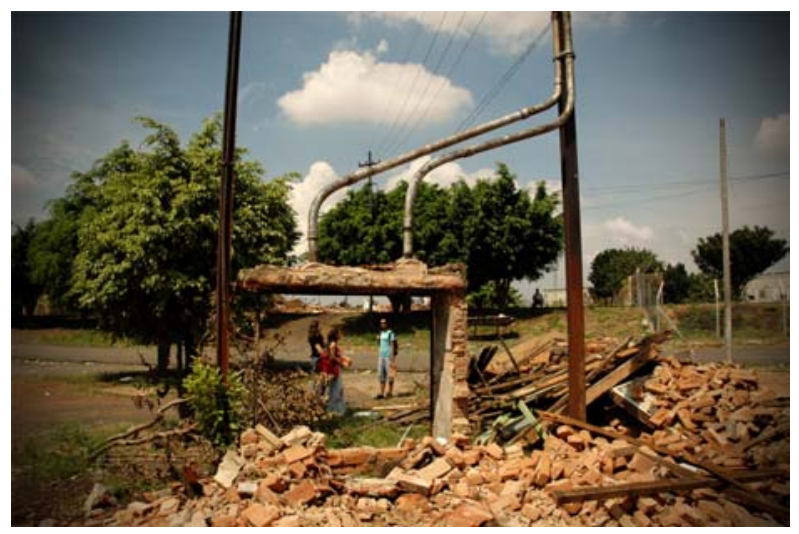

Foto 04: Cena da demolição presenciada pelos alunos.

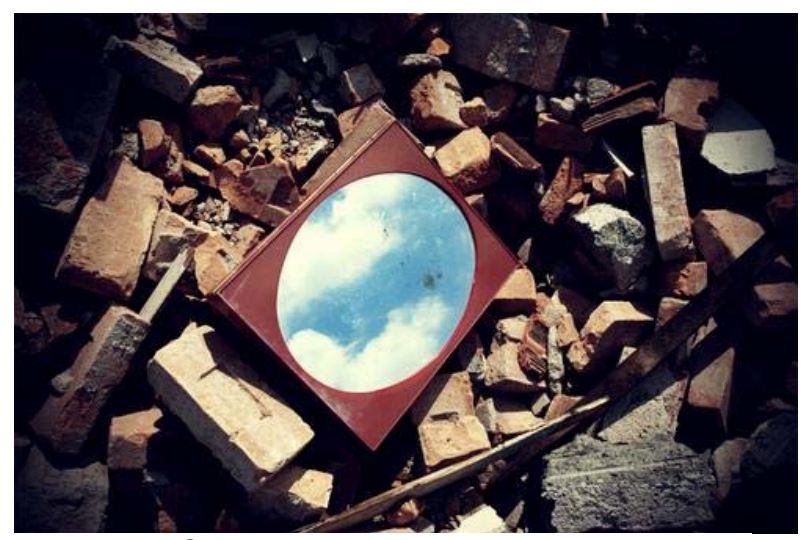

Foto 06: Os objetos dos moradores em meio aos escombros. 
Essas construções, antes existentes naquele local, eram mais do que meros exemplares tipológicos. Representavam oportunidades únicas para o estudo e compreensão desse tipo de arquitetura brasileira, que a partir dessa data, ficaram somente na memória daqueles que tiveram a oportunidade de conhecê-las. Nossa verdadeira indignação decorre da postura dos órgãos públicos frente tais bens que, ignorando a necessidade de planejamento, estudo e manutenção dos edifícios históricos, destruiu um patrimônio pertencente a todos sem ao menos técnicas construtivas e materiais componentes destas tipologias arquitetônicas pudessem ser estudados e documentados. De forma a testemunhar as mudanças e criação da vida quotidiana da cidade de Campinas, bem como contribuir para a produção arquitetônica e urbanística em geral. Todas essas considerações nos fazem refletir sobre a atuação dos profissionais e estudantes de arquitetura frente à manutenção e conservação do patrimônio. Estamos nos mobilizando de fato para alterar o crescente descaso e ignorância em relação ao patrimônio histórico e cultural das nossas cidades? 

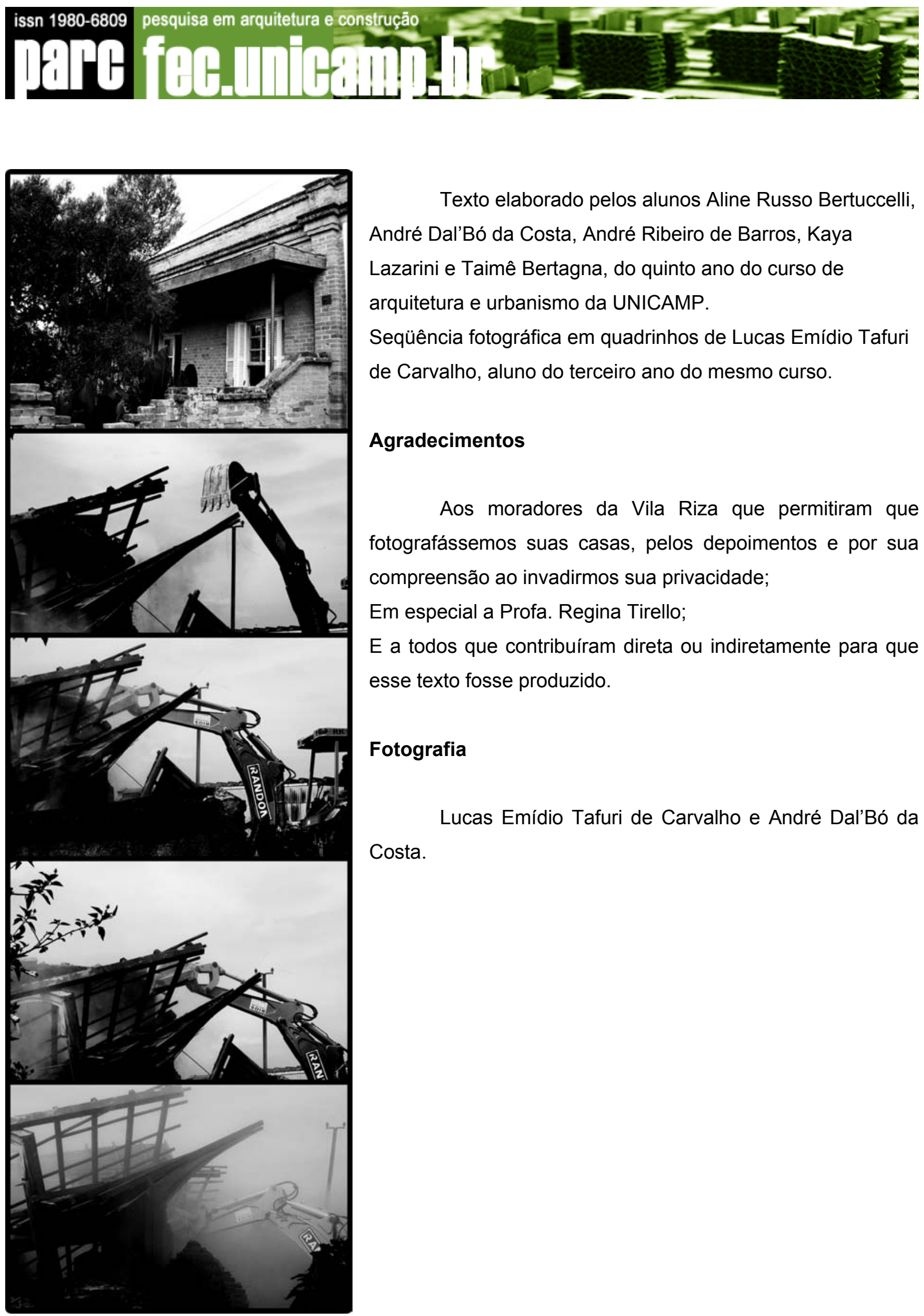

Texto elaborado pelos alunos Aline Russo Bertuccelli, André Dal'Bó da Costa, André Ribeiro de Barros, Kaya Lazarini e Taimê Bertagna, do quinto ano do curso de arquitetura e urbanismo da UNICAMP.

Seqüência fotográfica em quadrinhos de Lucas Emídio Tafuri de Carvalho, aluno do terceiro ano do mesmo curso.

\section{Agradecimentos}

Aos moradores da Vila Riza que permitiram que fotografássemos suas casas, pelos depoimentos e por sua compreensão ao invadirmos sua privacidade;

Em especial a Profa. Regina Tirello;

$\mathrm{E}$ a todos que contribuíram direta ou indiretamente para que esse texto fosse produzido.

\section{Fotografia}

Lucas Emídio Tafuri de Carvalho e André Dal'Bó da Costa. 


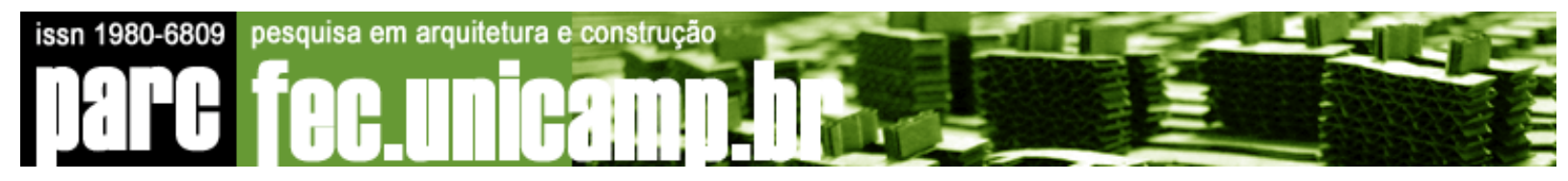
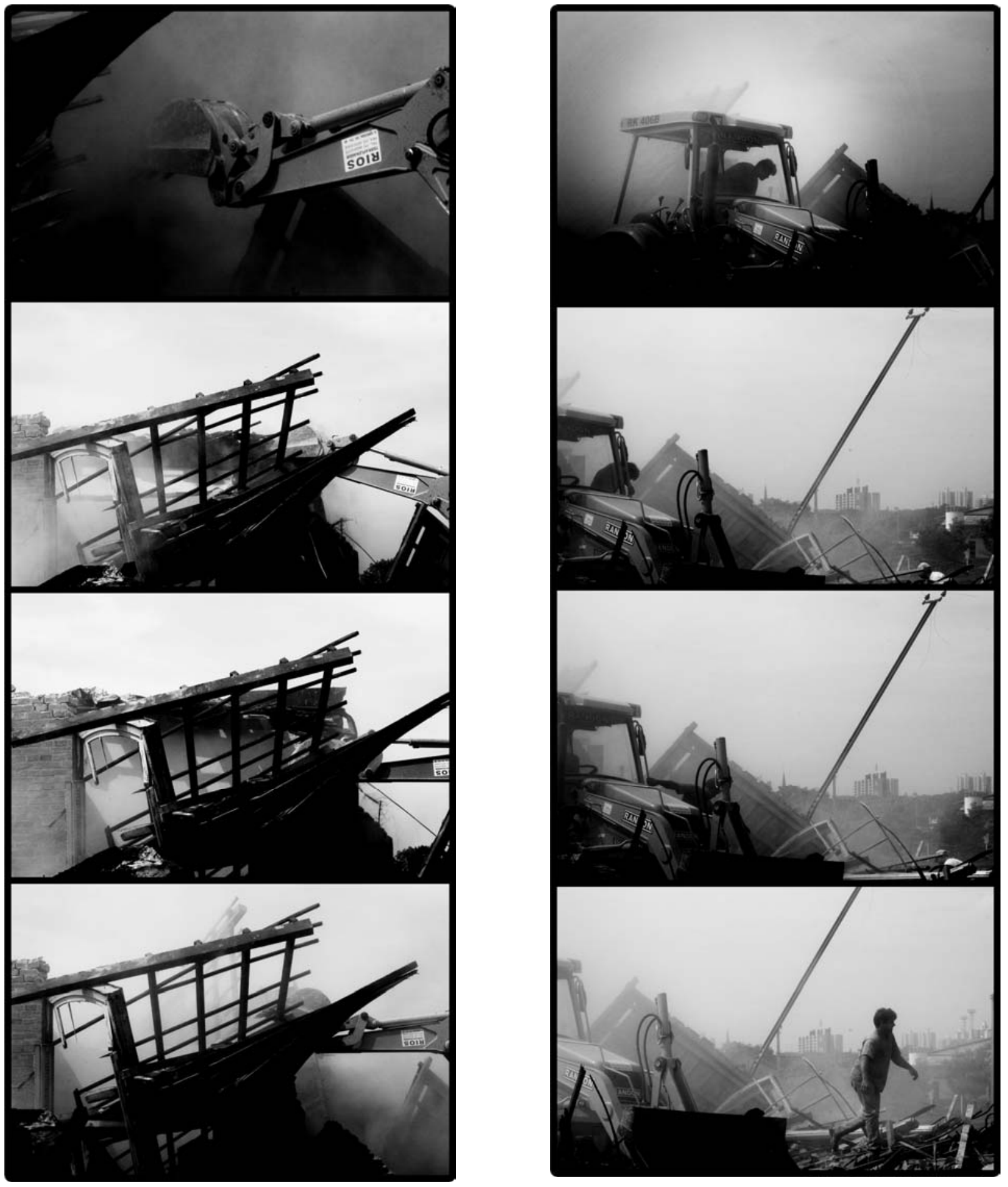


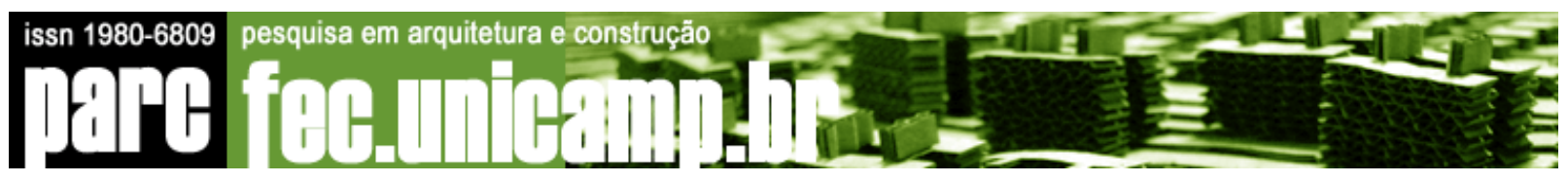

\section{Referências}

WIECZOREK, Daniel. Introduction du traducteur. In: RIEGL, Aloïs. Le culte moderne des monuments. Son essence et sa genèse. 1984.

CHOAY, Françoise. A Alegoria do Patrimônio. São Paulo: Editora da UNESP, 2001.

\section{Internet:}

http://www.revista.iphan.gov.br/materia.php?id=179

http://www.abpf.org.br/museu.htm

http://www.ocomboio.net/pages/patrimonio.html

Sites consultados entre os dias 2 e 11 de maio de 2007 :

- Disciplina AU 814 - Técnicas Retrospectivas, ministrada pela Prof. Dra. Regina A. Tirello no curso de Arquitetura e Urbanismo da Faculdade de Engenharia Civil, Arquitetura e Urbanismo, UNICAMP. 